\title{
Neural and psychophysiological correlates of human performance under stress and high mental workload
}

\author{
Kevin Mandrick ${ }^{\mathrm{a}}$, Vsevolod Peysakhovich ${ }^{\mathrm{a}}$, Florence Rémy ${ }^{\mathrm{b}}$, Evelyne Lepron ${ }^{\mathrm{b}}$, \\ Mickaël Causse ${ }^{a, *}$ \\ a ISAE (Institut Supérieur de l'Aéronautique et de l'Espace), Toulouse, France \\ b Centre de recherche Cerveau et Cognition, Université de Toulouse UPS and CNRS, Toulouse, France
}

\section{Keywords:}

Mental effort

Stress

Prefrontal cortex

Cardiovascular activity

Pupil response

Functional near-infrared spectroscopy

\begin{abstract}
A B S T R A C T
In our anxiogenic and stressful world, the maintenance of an optimal cognitive performance is a constant challenge. It is particularly true in complex working environments (e.g. flight deck, air traffic control tower), where individuals have sometimes to cope with a high mental workload and stressful situations. Several models (i.e. processing efficiency theory, cognitive-energetical framework) have attempted to provide a conceptual basis on how human performance is modulated by high workload and stress/anxiety. These models predict that stress can reduce human cognitive efficiency, even in the absence of a visible impact on the task performance. Performance may be protected under stress thanks to compensatory effort, but only at the expense of a cognitive cost. Yet, the psychophysiological cost of this regulation remains unclear. We designed two experiments involving pupil diameter, cardiovascular and prefrontal oxygenation measurements. Participants performed the Toulouse N-back Task that intensively engaged both working memory and mental calculation processes under the threat (or not) of unpredictable aversive sounds. The results revealed that higher task difficulty (higher $n$ level) degraded the performance and induced an increased tonic pupil diameter, heart rate and activity in the lateral prefrontal cortex, and a decreased phasic pupil response and heart rate variability. Importantly, the condition of stress did not impact the performance, but at the expense of a psychophysiological cost as demonstrated by lower phasic pupil response, and greater heart rate and prefrontal activity. Prefrontal cortex seems to be a central region for mitigating the influence of stress because it subserves crucial functions (e.g. inhibition, working memory) that can promote the engagement of coping strategies. Overall, findings confirmed the psychophysiological cost of both mental effort and stress. Stress likely triggered increased motivation and the recruitment of additional cognitive resources that minimize its aversive effects on task performance (effectiveness), but these compensatory efforts consumed resources that caused a loss of cognitive efficiency (ratio between performance effectiveness and mental effort).
\end{abstract}

\section{Introduction}

\subsection{Mental effort and stress}

In our anxiogenic and stressful world, the maintenance of an optimal cognitive performance is a constant challenge. It is particularly true in complex working environments (e.g. flight deck, air traffic control tower), where individuals have sometimes to

* Corresponding author at: ISAE-SUPAERO, DCAS, 10 Avenue Edouard Belin, 31055 Toulouse, France.

E-mail address: mickael.causse@isae.fr (M. Causse). cope with a high mental workload (Borghini, Astolfi, Vecchiato, Mattia, \& Babiloni, 2014) and stressful (Causse, Dehais, \& Pastor, 2011) or unexpected situations (Causse et al., 2013). According to several authors, contexts of high mental workload (e.g., Causse, Peysakhovich, \& Fabre, 2016; Durantin, Gagnon, Tremblay, \& Dehais, 2014) and/or stress (e.g. Arnsten, 2009; Qin, Hermans, Marle, Luo, \& Fernández, 2009; Schoofs, Wolf, \& Smeets, 2009) may result in transient impairments of working memory (WM) and executive functions (Starcke, Wiesen, Trotzke, \& Brand, 2016). Also, as suggested by Davis, Walker, Miles and Grillon (2010) the expectancy of an unpredictable and uncontrollable stressor (in this paper, "stress" stands for the emotional tension associated with a sustained state of anxiety in response to the threat of a nega- 
tive event) is sufficient to create a threatening context and may deliver an emotional tension associated with a sustained anxiety (Breier et al., 1987; Lupien, Maheu, Tu, Fiocco, \& Schramek, 2007), at least when the pending stimulus is sufficiently aversive (Grillon, Baas, Lissek, Smith, \& Milstein, 2004). For example, threat induction using aversive loud sounds has been shown to actually induce higher tonic and phasic stress compared to predictable situations (Barrett \& Armony, 2006; Breier et al., 1987).

Literature shows that there is no straightforward effect of stress on cognitive performance, and human brain does not seem defenseless against adverse effects of stressful situations. For example, stress can disrupt WM, and, reciprocally, WM can modulate anxious response (Schmeichel, Volokhov, \& Demaree, 2008). Two important models (the processing efficiency model and the cognitive-energetical framework) have attempted to provide a conceptual basis on how human performance is modulated by high workload and stress/anxiety. Firstly, the processing efficiency theory (Eysenck \& Calvo, 1992) proposes that adverse effects of anxiety are not always visible on performance outcome. The authors posit that worries are triggered in stressful situations and that they have two main effects. The first effect involves cognitive interference by preempting the processing and storage capacity of working memory. The second effect involves increased motivation to minimize the aversive anxiety state. This latter function promotes enhanced effort and use of auxiliary processing resources and strategies. Thus, potential performance impairments caused by the preemption of working memory resources can be compensated if auxiliary processing resources are available. The theory discriminates performance effectiveness (quality of performance) and processing efficiency (ratio between performance effectiveness and mental effort). Given the triggering of compensatory mechanisms (e.g. enhanced effort; increased use of processing resources), impaired performance effectiveness is less likely to occur but at the cost of reduced efficiency. Attentional control theory (Eysenck, Derakshan, Santos, \& Calvo, 2007), a major development of Eysenck and Calvo's (1992) model, assumed that anxiety effects on processing efficiency concern primarily two central executive functions involving attentional control: inhibition and shifting. However, the authors posited that anxiety also impairs processing efficiency (and sometimes performance effectiveness) on tasks involving the updating function of working memory when the conditions are stressful.

The processing efficiency model has similarities with the second model, the cognitive-energetical framework. This latter model posits the existence of compensatory control in the regulation of human performance under stress and high workload (Robert \& Hockey, 1997). The cognitive-energetical framework also predicts that performance may be protected under stress by the recruitment of further resources, but only at the expense of increased subjective effort, and behavioral and physiological costs. Even when no primary task decrements are detected, performance may show disruption of subsidiary activities or the use of less efficient strategies. Additional costs include increased psychophysiological activation, strain, and fatigue after-effects. Otherwise, cost stability can be achieved by reducing performance goals. Beyond their respective theoretical constructs, the common idea in the processing efficiency theory (Eysenck \& Calvo, 1992) and the cognitive-energetical framework (Robert and Hockey, 1997) is that stress likely triggers increased motivation and the recruitment of additional cognitive resources that minimize its aversive effects on task performance (effectiveness). However, these compensatory efforts consume resources and thus, cause a loss of cognitive efficiency.

The impact of stress seems to also depend on task difficulty (Robinson, Vytal, Cornwell, \& Grillon, 2013). Patel et al. (2015) recently showed that the threat of an aversive loud scream impacted WM performance at low and medium but not high load conditions. Consistently, Clarke and Johnstone (2013) found that the threat of shock significantly disrupted the cognitive performance under low WM load whereas no significant interference (and even a trend for performance improvement) occurred in the high WM load condition. Such results may be interpreted as a reduced distractor effect (Hu, Bauer, Padmala, \& Pessoa, 2012), when attention is shifted away from the affective stimulus (Pessoa, McKenna, Gutierrez, \& Ungerleider, 2002; Van Dillen, Heslenfeld, \& Koole, 2009), and suggest the existence of a dynamic balance between emotion and cognition (Drevets \& Raichle, 1998). Such a balance is also supported by results from Berggren, Richards, Taylor and Derakshan (2013). In their study, emotion was deleterious to performance in the low load condition (tones recognition) during a modified emotional antisaccade task (a condition in which gaze towards emotional stimuli should be inhibited and participants had to look away from the image and move their eyes to the opposite end of the screen). On the contrary, emotion did not influence performance under the high load condition (recognition of specific tone pitch), supporting recent evidence that more complex cognitive processes can reduce emotional influences on attention and cognition.

\subsection{Psychophysiological activity related to cognition and emotion}

According to Ryu and Myung (2005), physiological measures can be classified into three major categories as a function of the physiological organs involved: brain-related measures, eyerelated measures, and heart-related measures. Prefrontal cortex (PFC) related activity is modulated by WM load, for example, Owen, McMillan, Laird and Bullmore (2005) meta-analysis of 24 -back studies has shown that higher workload is consistently associated with greater cortical activation, including critical PFC regions. Recent studies also showed that activations of the PFC observed via functional near infrared spectroscopy (fNIRS) reflect WM load during $n$-back tasks (Fishburn, Norr, Medvedev, \& Vaidya, 2014; Gateau, Durantin, Lancelot, Scannella, \& Dehais, 2015; Herff et al., 2014; Peck, Afergan, Yuksel, Lalooses, \& Jacob, 2014; Sato et al., 2013; Yuksel et al., 2015). It is also clear that the PFC is one of the most sensitive brain regions to the detrimental effects of stress (Arnsten, 2009), because it has a critical role in the integration of cognitive and affective behavior (Cerqueira, Almeida, \& Sousa, 2008). In particular, the orbital and medial PFC are known to be involved in regulation of emotion via extensive connections with limbic regions (Hänsel \& Känel, 2008; Seo and Sinha, 2011(ch9)). Interestingly, dorsolateral PFC is also likely to indirectly contribute to emotion regulation through its interaction with the orbitofrontal cortex and the anterior cingulate cortex, and via these areas, with the amygdala (Salzman \& Fusi, 2010a, 2010b). In addition, the dorsolateral PFC may be also involved in emotion regulation because it plays a crucial role in the neural network subserving WM functions (Levy and Goldman-Rakic, 2000). As suggested by Schmeichel, Volokhov and Demaree (2008), WM capacity contributes to the control of emotional response as subjects with higher WM capacity suppressed expressions of negative and positive emotion better than subjects with lower WM capacity did. Several fNIRS studies have investigated the impact of emotion on the PFC during a stressful situation (Doi, Nishitani, \& Shinohara, 2013; Morinaga et al., 2007; Tanida, Katsuyama, \& Sakatani, 2007; Tupak et al., 2014). Tanida et al. (2007) indicated that mental stress induced a predominance of the right PFC activation, revealed by an increase of $\mathrm{HbO}_{2}$ signal with a concomitant decrease of the HHb signal. In addition, Morinaga et al. (2007) showed higher activation of the right PFC activation (an increase of $\mathrm{HbO}_{2}$ ) during anticipation of shocks.

The pupil diameter is a well-established measure of WM load (Andreassi, 2000; Beatty, 1982; see also Laeng, Sirois, \& Gredebäck, 2012, for a recent review). First viewed as a simple measure of "intensity" of attention and mental activity (Kahneman \& Beatty, 
1966; Kahneman, 1973), it is now admitted that pupil diameter is also a relevant indicator of affective and emotional processing (Bitsios, Szabadi, \& Bradshaw, 1998; Bradley, Miccoli, Escrig, \& Lang, 2008; Clarke \& Johnstone, 2013; Partala \& Surakka, 2003). Cohen, Moyal and Henik (2015) used pupil dilation measurements to monitor the emotional response generated by aversive stimuli (pictures and sounds). They showed that emotional response was attenuated, as indexed by lower pupil dilation, when the aversive stimuli were preceded by incongruent flanker stimulus, providing evidence that the physiological response associated with emotional stimulation depends on situational demands, such as prior activation of executive control processes. However, the authors did not explicitly manipulate the mental workload in their paradigm.

Also, task-related psychophysiological costs have been studied with the analysis of the cardiovascular activity (Riese, 1999). Subjects react to sustained heavy task demands by an initial reaction called the defense reaction. This reaction is supposed to be caused by increased activation of the sympathetic nervous system and inhibition of the vagal system, inducing classical cardiovascular reactions: an increase in blood pressure and heart rate (HR) and a decrease in heart rate variability (HRV) (Riese, 1999; Causse, Baracat, Pastor, \& Dehais, 2011). It is also well demonstrated that HR and HRV provide sensitive markers to emotional processes (e.g. Brosschot \& Thayer, 2003; Lane et al., 2009; McCraty, Atkinson, Tiller, Rein, \& Watkins, 1995; Quintana, Guastella, Outhred, Hickie, \& Kemp, 2012). For example, Brosschot and Thayer (2003) showed that moderate increase of HR (approximatively 1 beat per minute) can last up to $5 \mathrm{~min}$ after negative events.

Because the relationship between psychology and psychophysiological reaction is not always one-to-one (e.g. one psychological operation associated with one psychophysiological reaction), but also many-to-one, one-to-many, or many-to-many (Cacioppo \& Tassinary, 1990), as Zhou, Qu, Helander and Jiao (2011) we suggest that a single psychophysiological measure is not adequate to give a full picture of the ongoing psychological processes, particularly when both cognitive and emotional variables are manipulated. In the present study, combined eye-related, heart-related, and brainrelated measures were conducted.

\subsection{Present study}

We studied the effects of stress (induced by the threat of unpredictable aversive loud sounds) on WM performance under variations of task difficulty. We designed a new task, the Toulouse N-back Task (TNT), combining the classical $n$-back task with mathematical processing to induce different levels of mental workload. The task allows eliciting both a sustained high WM and processing load, which mimics the multidimensional high mental workload existing in many safety-critical occupations. The purpose of the present study was to explicitly investigate the impact of mental effort and stress in a highly demanding task, by assessing performance as well as the psychophysiological cost involved. In addition to the well admitted deleterious impact of high mental workload (Causse et al., 2016; Durantin et al., 2014), we may hypothesize that task performance would be impacted by stress. On the other hand, various models such as processing efficiency theory and the cognitive-energetical framework also suggest that we may not observe any behavioral effect of stress: cognitive performance may be protected under stress thanks to compensatory efforts and the use of cognitive coping strategies, but only at the expense of a psychophysiological cost (Robert \& Hockey, 1997). Yet, reduced cognitive efficiency and/or the cost of strategies to cope with stress are generally examined through variation in task performance (eg. longer reaction times), but their psychophysiological correlates remain unclear. We hypothesized that pupil diameter, HR, and prefrontal cortex oxygenation would be higher in the condition of high mental workload and also in the condition of stress. Finally, as suggested by various authors, we may also observe an interaction between mental workload and stress in a way that the high WM load condition could mitigate the impact of stress. This lowered impact of emotion might be indexed by behavior and psychophysiological measurements.

\section{Materials and methods}

\subsection{Participants}

We recruited fourteen healthy volunteers (5 women, age $25.8 \pm 3.8$ years) for study 1 and twenty healthy volunteers ( 5 women, age $24.6 \pm 4.8$ years) for study 2 . Pupillometry recordings were performed in Study 1 and fNIRS recordings were performed in Study 2. Cardiovascular activity was recorded in both studies. Participants were split into two separate studies as simultaneous functional near-infrared spectroscopy and pupillometry measurement is complex because these two techniques overlap in the near-infrared wavelength band. All were students at National Civil Aviation School (ENAC) and Higher Institute of Aeronautics and Space Engineering School (ISAE) in Toulouse, France. None reported neither affective or anxiety disorder, nor any neurological or cardiovascular disease. None was under medication that might affect the brain or autonomic functions. All volunteers reported normal auditory acuity and normal or corrected-to-normal vision. All participants gave written informed consent in accordance with local ethical board committee. The study complied with the Declaration of Helsinki for human experimentation and was approved by medical Committee (CPP du Sud-Ouest et Outre-Mer IV, n ${ }^{\circ} \mathrm{CPP} 15-$ 010b/2015-A00458-41).

\subsection{Mental arithmetic N-back task (Toulouse N-back task)}

The new $n$-back task, called TNT, was developed for this study in order to combine a classical $n$-back task with mental arithmetic (Fig. 1). Instead of memorizing and comparing unique items, as in the classical $n$-back task, the participants had to memorize and to compare the results of arithmetic operations, computed beforehand. In each trial, volunteers were required to compute the result and compare it with either a fixed number (0-back) or the result obtained 1 (1-back) or 2 (2-back) trials before. Arithmetic operations were either additions or subtractions, of which all summands were a multiple of 5 (e.g., $15+40,90-35$ ). Therefore, WM load was variable between conditions, with the 2 -back task generating the highest load. During the resting periods, screens with " $00+00$ " operations were presented and volunteers did not have to give any response.

Operations were displayed in the center of a gray background. Participants were given a 2-button Cedrus response pad (RB-740, Cedrus Corporation, San Pedro, CA) and were asked to press either a green button if the result matched the target number or a red button if not. Participants had to give their response as quickly as possible. The task was implemented in Matlab (MathWorks) using the Psychophysics Toolbox (Psychtoolbox 3, Kleiner, Brainard, \& Pelli, 2007).

\subsection{Threat using auditory stressors}

Stress (i.e. sustained anxiety) was induced with the threat of unpredictable loud sounds (Patel et al., 2015). The auditory stressors occurrence was non-contingent upon the task performance. We created a set of 34 aversive sounds inspired from the literature (Grillon, Pine, Lissek, Rabin, \& Vythilingam, 2009; Hirano et al., 2006; Kumar, Forster, Bailey, \& Griffiths, 2008; Zald \& Pardo, 2002). The sounds were perceived as mildly stressful, uncomfortable and 


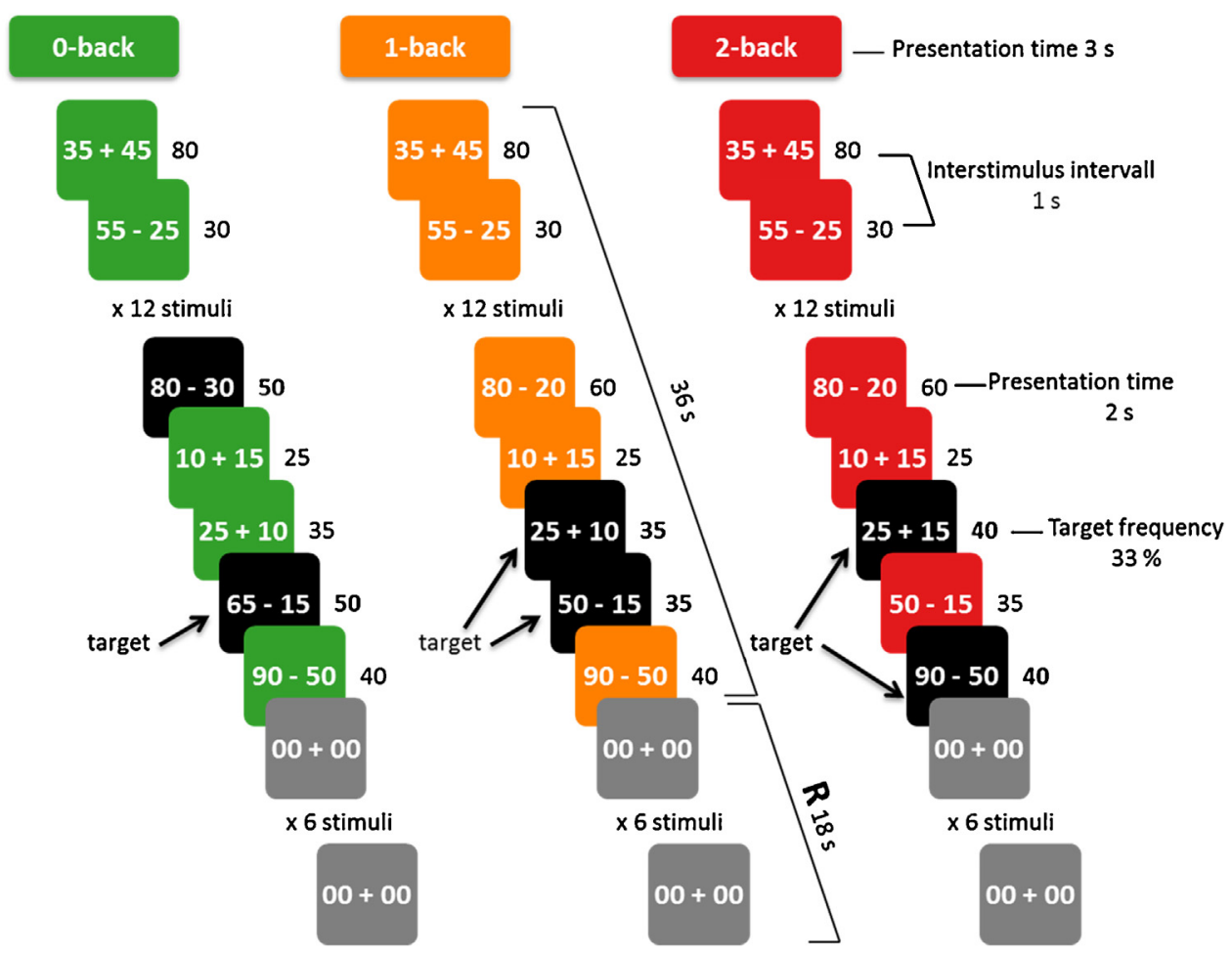

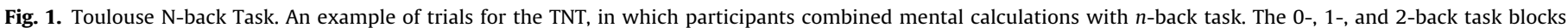

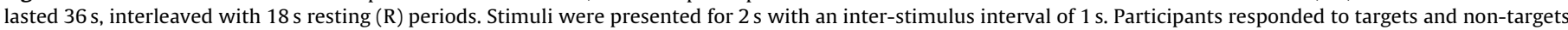

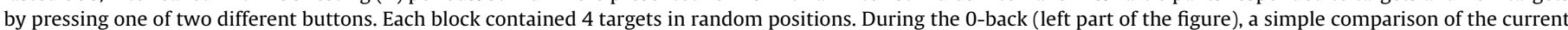

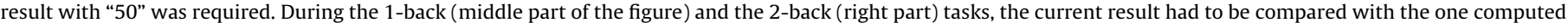
1 or 2 trials before, respectively.

unpleasant by 87 participants during a pilot study (ratings $>6$ using a 10-point scale, with 10 meaning "extremely unpleasant and stressful together").

The stressfulness of the sounds was also validated by a spectral frequency-temporal modulation analysis (see Supplementary material). Sounds were modified to equalize loudness and duration. Each sound sample was presented only once to prevent habituation and make the stimulation more salient and stressful. Participants were informed that they would be exposed to different unpredictable aversive loud sounds during a given block or resting period. However, the onset of sounds was unknown to participants in order to maintain a continuous threat (Grillon et al., 2009; Zald \& Pardo 2002). The sounds were played for $7 \mathrm{~s}$ via AKG K171 MkII monitor headphones in stereo mode and at a 95-dB sound pressure level, as controlled using a noise meter (Grillon et al., 2009; Hirano et al., 2006).

\subsection{Subjective difficulty measures}

Following a training period with the TNT, participants rated difficulty using a DP15 scale (Delignières, Famose, \& Genty, 1994). The DP15 scale consists in a 15-point category scale, with 7 labels, from 2 (extremely easy) to 14 (extremely difficult), symmetrically placed around a central label 8 (somewhat difficult).

\subsection{Subjective anxiety measures}

\subsubsection{Sensitivity to auditory stressors}

To assess individual sensitivity to auditory stressors, participants were requested to listen to each of the 34 aversive loud sounds (presented with illustrative images) - before or after the experiment, the order was counterbalanced across participants - and to rate each sound unpleasantness and induced-stress using a 10 -point scale (with 10 meaning "extremely unpleasant and stressful together").

\subsubsection{Anxiety questionnaire}

Subjective evaluation of the anxiety state was obtained by two completions of the State-Trait Anxiety Inventory (STAI form Y-A, French translation) (Gauthier \& Bouchard, 1993), preceding and following the whole experimental protocol. This test consisted of a 20-item self-administered questionnaire with 4-point Likert scale response (Spielberger, Gorsuch, \& Lushene, 1970).

\subsection{Experimental procedure}

Participants were first trained for each level of the TNT through a short sequence of $5 \mathrm{~min}$, in which aversive loud sounds were presented randomly. Experimental runs consisted of a first 10-s fNIRS baseline followed by alternating TNT and rest blocks. Two runs included unpredictable aversive loud sounds ("threat" runs) and one run was without any threats ("safe" run). The order of the TNT blocks within a run and the order of "threat" and "safe" runs were counterbalanced across participants. To avoid fatigue, a short break lasting approximatively $5 \mathrm{~min}$ was given at the end of each run. Before and during TNT blocks, a 3-s instruction screen was displayed to inform the participant about upcoming TNT difficulty ("0-back", "1-back", "2-back") and about threat condition (safe vs. threat) (Fig. 2). During the safe run, participants were reminded that no sound will be played. During threat runs, participants were reminded that aversive loud sounds may occur at any time, including during resting periods.

The safe run included 12 blocks ( 4 blocks of each difficulty). The two threat runs included 9 blocks each ( 3 blocks of each 


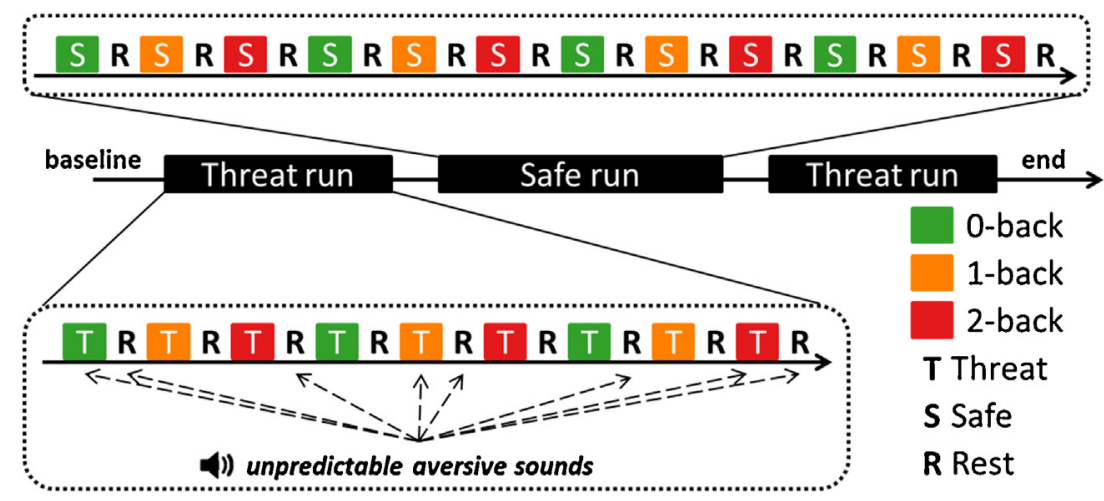

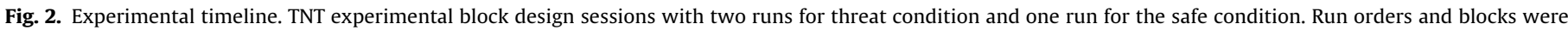
counterbalanced and pseudo-randomized. Unpredictable aversive loud sounds were played randomly during a threat run and could occur during resting period.

difficulty). For the analysis of the threat runs, we discarded the blocks containing sounds ( 6 blocks in total) to exclude any potential effect of sound distraction and to focus on the stress related to the expectancy of the unpredictable sounds (Clarke \& Johnstone, 2013). We thus compared the 12 threat blocks in which participants expected, but did not actually hear sounds, with the 12 safe blocks. Hence, 4 blocks ( $4 \times 12$ trials) per condition (0-, 1-, 2-back x Safe, Threat) were included in the analyses. For the pupillary analyses, 12 blocks of resting periods ( $12 \times 6$ trials) were also included.

\subsection{Behavioral measurements}

TNT accuracy was calculated using the d-prime measure, computed as follows: $z$ (hit rate) $-z$ (false alarm rate). Additionally, the number of misses (no response) was computed, this latter measure likely reflecting an exhaustion of cognitive resources.

\subsection{Study 1: Pupillometry measurements}

Participants were seated at approximately $70 \mathrm{~cm}$ from a $22^{\prime \prime}$ computer screen $(1680 \times 1250$ pixels $)$. Ambient luminance was of $10 \mathrm{~lx}$. During the whole experiment, participants' gaze position and pupil diameter were tracked using a remote SMI RED500 eye-tracker (SensoMotoric Instruments GmbH, Germany) at a sampling rate of $120 \mathrm{~Hz}$. This device allows tracking the pupil despite small head movements. Before each run, participants performed a 5 -point calibration procedure validated with 4 additional fixation points. The data acquisition routine used iViewX SDK to communicate with Matlab software. Periods of signal loss and blinks (both were marked as zeros by the eye-tracking system) were linearly interpolated. Then the signal was filtered with a two-pass 9-point filter (low-pass with a cutoff frequency of $5.9 \mathrm{~Hz}$ ). For tonic pupil diameter analyses, we used the median pupil diameter value for each block. We also conducted (event-related) phasic pupillary response analyses. For this analysis, the pupillary recordings were segregated in 3-s segments corresponding to each trial. For all participants, an average phasic pupillary response was obtained for each condition. A trial was excluded if the total duration of signal loss or blinking exceeded 50\% (1.5 s) or if median gaze position during the trial deviated from the screen center of more than 150 pixels. An average of $44.6(S D=8.4)$ trials out of 48 were validated per experimental condition. An average of $58.1(\mathrm{SD}=14.6)$ trials out of 72 were validated for resting periods. The number of validated trials was non-dependent on the condition $(p>0.05)$. Median values calculated on the 500 -ms period preceding the trial onset were used as baselines. For statistical analyses of phasic pupil response, we used the maximum pupil diameter in the interval between 1 and $2 \mathrm{~s}$ post-stimulus. Resting periods were included in the pupil-

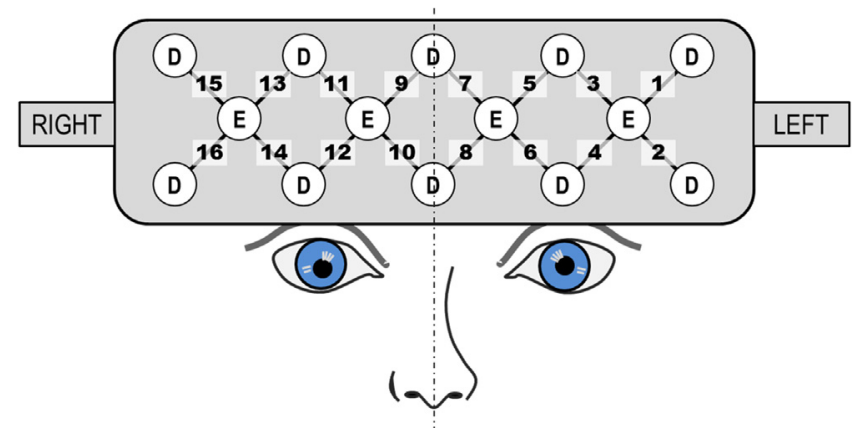

Fig. 3. fNIRS headband. Location of the optodes on participant's forehead with a flexible fNIRS sensor pad labeled from channel 1 to channel 16. Emitters are marked as $\mathrm{E}$ and $\mathrm{D}$ indicates detectors. Areas underlying the channel are approximately over Brodmann's areas 10 and 46.

lometry analyses to confirm that the pupillary reaction was due to the psychophysiological phenomenon and not visual factors. Thirteen participants were included in the pupillary analyses (pupil data from one participant were discarded due to technical issues during the recording).

\subsection{Study 2: Functional near infrared spectroscopy measurements}

To illuminate the forehead, a CW fNIRS 16-channel headband model 100 fNIRS system (fNIRS Devices LLC, Photomac MD; http:// www.fnirdevices.com) was used to obtain raw light intensity by specific dual wavelengths of $730 \mathrm{~nm}$ and $850 \mathrm{~nm}$ (Fig. 3). Data were acquired at a frequency of $2 \mathrm{~Hz}$ for all 16 channels.

At the beginning of the experiment, participants were equipped with the fNIRS headband. The $10 \mathrm{~s}$ baseline was taken at rest with eyes closed. fNIRS-PFC activity was recorded through the entire experiment. COBI Studio software (Drexel University) was used for data acquisition and visualization of the 16 channels then the version 4.0 of fnirSoft software package was used for filtering, converting and analyzing data (Ayaz, 2010). First, the raw optical density signals were converted to concentration changes of oxygenated hemoglobin $\left(\mathrm{HbO}_{2}\right)$ and deoxygenated hemoglobin $(\mathrm{HHb})$ using the modified Beer-lambert law. fNIRS data were then bandpass filtered using a FIR filter of order 20 and cutoff frequencies of 0.01 and $0.1 \mathrm{~Hz}$. No detrending was applied. Then, available optodes were averaged in 3 regions of interest for each participant; left prefrontal cortex (optodes 1-6), frontopolar prefrontal cortex (optodes 7-10), right prefrontal cortex (optodes 11-16). Eight participants had missing fNIRS data in a few medial optodes for at least one experimental condition due to poor contact with the forehead (i.e. 
optodes 5, 7-9, and 10). At most, 3 optodes were missing for 1 participant, thus a measure of the frontopolar prefrontal cortex activity was possible for these 8 participants. To dissociate effects of TNT difficulty (0-back vs. 1-back vs. 2-back) and threat (safe vs. threat), we extracted the fNIRS response from each block. Signals were normalized towards zero by subtracting the current signal with the first data point. Then, signals were averaged on all trials for each condition.

We calculated the blood-oxygenation response determined as the difference between $\mathrm{HbO}_{2}$ and $\mathrm{HHb}$ signals. For fNIRS data analysis, we compared the blood-oxygenation response with the analysis of the response amplitude (the difference between the mean value of the first and the last 10 s of each block) (Mandrick et al., 2013a, 2013b). Seventeen participants were included in the fNIRS analyses (fNIRS data of three participants were excluded, one due to excessively noisy signal and two due to recording problems).

\subsection{Cardiovascular activity}

Cardiovascular activity (by 1-lead ECG) was continuously recorded in both studies. Signals were sampled at $500 \mathrm{~Hz}$ in a synchronous manner using a Biopac MP150 Hardware and Biopac AcqKnowledge 4.1.1 Software (Biopac Systems Inc., CA, USA). Signal was derived into RR intervals to assess the HR. Data sets were visually controlled for outliers and artifacts. Analyses were conducted with Kubios HRV software 2.2 (University of Eastern Finland, http:// kubios.uef.fi). We investigated total HRV via the root mean square of successive differences (RMSSD) (Task Force of the European Society of Cardiology the North American Society of Pacing, 1996). Thirty-three participants were included for the analysis of the cardiovascular activity (HR and HRV data of one participant was excluded due to excessively noisy signal).

Data analysis

Results were analyzed using Statistica software (StatSoft). Normality and homoscedasticity of data were assessed using Kolmogorov-Smirnov and Lilliefors tests, respectively. Pre -post comparisons of STAI scores and prefrontal oxygenation responses were carried out using Student paired $t$-test. Other data were analyzed using repeated-measures analyses of variance (ANOVA) for normally distributed variables (i.e. pupillometry, HR/HRV, and fNIRS measurements) and Friedman's ANOVA test for nonnormally distributed variables (i.e. DP15, d-prime, and\% no response). In the case of significant main effect or interaction, significant differences between conditions were identified using Tukey's HSD posthoc tests for normal distribution or Wilcoxon comparisons test for non-normal distribution. $p$-values were adjusted for multiple comparisons with the Holm-Bonferroni correction (Holm, 1979). A significance level of $p<0.05$ was used for all comparisons. Effect sizes were reported using partial eta-squared $\left(\eta_{p}^{2}\right)$.

\section{Results}

\subsection{Subjective difficulty ratings}

There was no significant difference between Study 1 and 2 $(p>0.05)$ (Mann-Whitney $U$ test for each variable; $p>0.05$ ) regarding the perceived difficulty during the familiarization session. Therefore, perceived difficulty data were pooled across studies and statistics were also calculated for 34 participants. DP15 ratings significantly increased with TNT difficulty ( $\mathrm{n}$ level) (Friedman's chi-square ANOVA $=65.5 ; p<0.001$ ), with ratings being higher for 1-back vs. 0 -back $(Z=5.03 ; p<0.001)$, for 2 -back vs. 0 -back $(Z=5.08$; $p<0.001)$, and for 2-back vs. 1 -back $(Z=5.01 ; p<0.001)$. The 0 -back task was rated as "very easy" (average DP15 $=4.5 \pm 2$ ), the 1 -back task as "somewhat difficult" (average DP15 =7.8 \pm 1.9 ), and the 2back task as "very difficult" (average DP15 $=11.9 \pm 1.6$ ).

\subsection{Subjective anxiety ratings}

Subjective ratings of induced stress for the 34 aversive loud sounds are given in Supplementary material. Based on this subjective report, a mean rating of $5.4 \pm 2.4$ was observed, confirming that sounds were mildly stressful.

There was no significant difference between Study 1 and 2 (ttest for each variable; $p>0.05$ ), therefore, anxiety ratings data were pooled across studies and statistics were calculated for 34 participants. Participants' anxiety score measured by STAI Y-A were significantly higher at the end of the protocol, relative to the beginning $(29.1 \pm 5.9$ versus $33.3 \pm 7.1$, respectively; $t=3.85 ; p<0.001)$. This outcome shows that the experiment produced an increased anxiety.

\subsection{Behavioral data}

There was no significant difference between Study 1 and 2 regarding the behavioral performance (Mann-Whitney $U$ test for each variable; $p>0.05$ ). Therefore, behavioral data were also pooled across studies and statistics were calculated for 34 participants. Cognitive scores for each $n$-back condition were assessed using dprime and percentage of miss ("no response") (Fig. 4). Participants showed lower d-prime scores with increased task difficulty (Friedman's chi-square ANOVA $=115.7 ; p<0.001)$. Post-hoc comparison revealed significant differences $(p<0.001)$ for all $n$-back level as summarized in Fig. 4. Similar results were observed for the percentage of omitted responses, which monotonically increased with
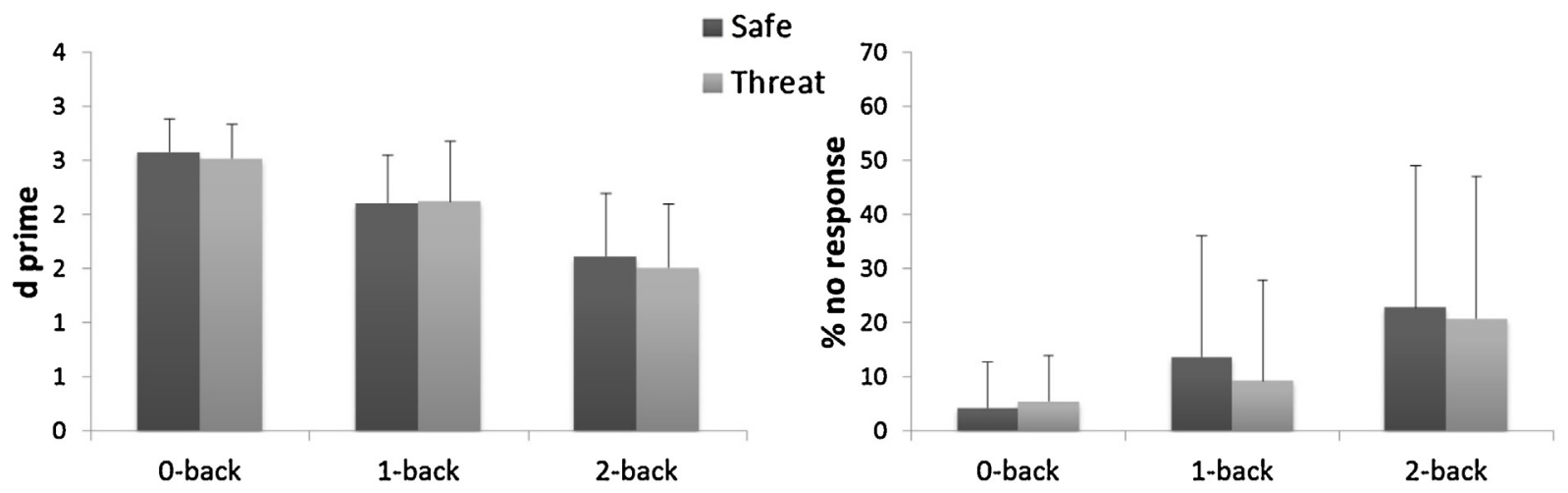

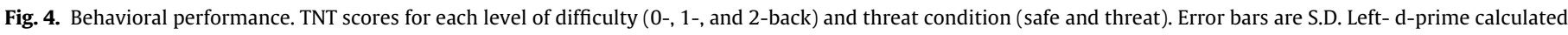
as $z$ (hit rate $)-z$ (false alarm rate). Right- the percentage of "no response". $n=34$. 

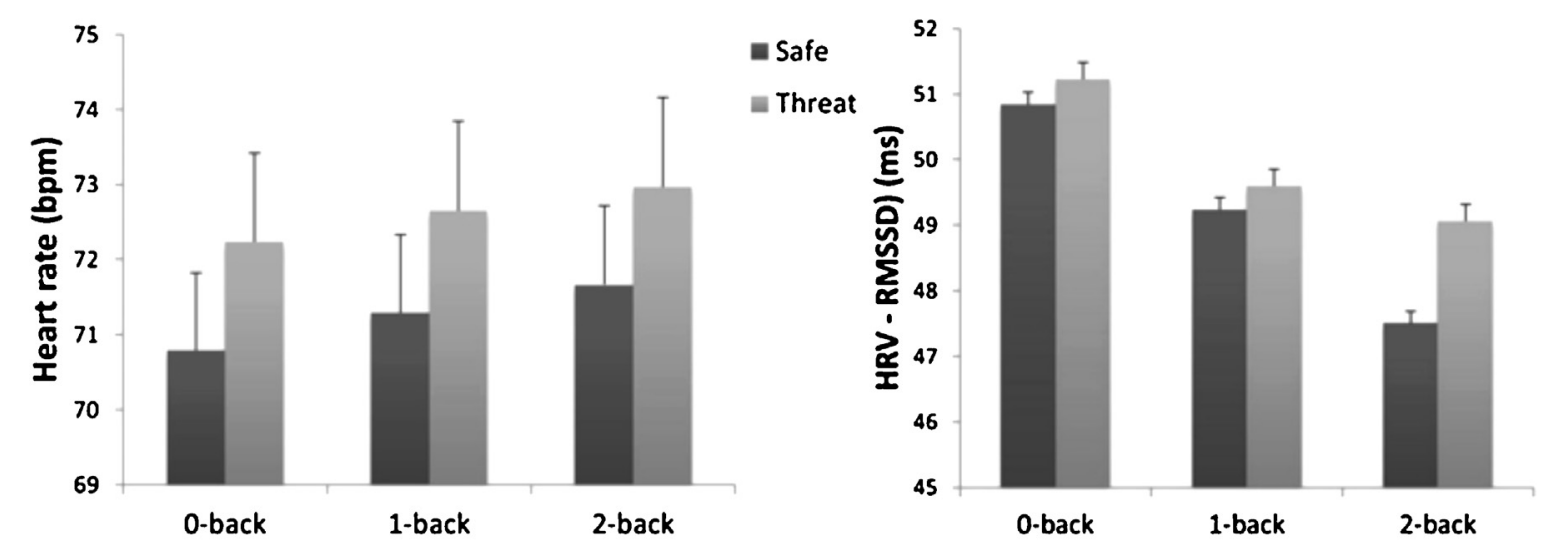

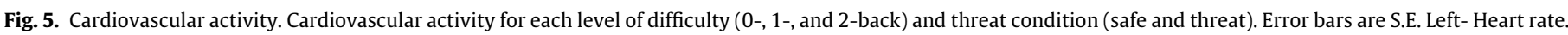
Right- Heart rate variability. $\mathrm{n}=33$.

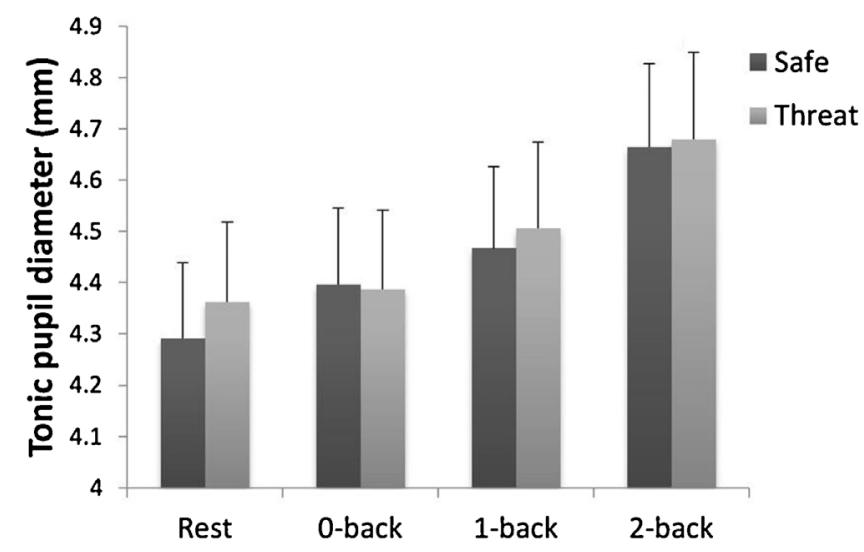

Fig. 6. Tonic pupil diameter. Bar height shows mean tonic pupil diameter for each level of difficulty (rest, 0-, 1-, and 2-back) and threat condition (safe and threat). Error bars represent S.E. $\mathrm{n}=13$.

task difficulty (Friedman's chi-square ANOVA = 57.9; $p<0.001$ ). The threat of unpredictable auditory stressors did not impact behavioral performance $(p>0.05)$.

\subsection{Cardiovascular activity}

There was no significant difference between study 1 and 2 $(p>0.05)$ regarding cardiovascular activity. Therefore, HR data were also pooled across studies and statistics were calculated for 33 participants. There was a significant elevation of the HR with increased TNT difficulty $\left(F_{2,62}=20.5 ; p<0.001 ; \eta_{p}{ }^{2}=0.40\right)$, with a monotonical increased across each level of difficulty (smallest $p$-value $=0.019$ ). HR was also impacted by stress, it was higher under the threat of the unpredictable aversive sounds $\left(F_{1,32}=4.35 ; p<0.05 ; \eta_{p}^{2}=0.12\right)$ (Fig. 5). There was also a significant decrease in HRV (RMSSD) with task difficulty $\left(F_{2,62}=12.1\right.$; $\left.p<0.001 ; \eta_{p}{ }^{2}=0.28\right)$, HRV was smaller in 0-back vs. 1 - and 2-back (smallest $p$-value $<0.001$ ) (Fig. 5). Finally, HRV was not impacted by stress $(p>0.05)$.

\subsection{Pupillometry}

\subsubsection{Tonic pupil diameter}

Tonic pupil diameter significantly increased with task difficulty $\left(F_{3,36}=26.27 ; p<0.001 ; \eta_{p}{ }^{2}=0.69\right)$ (Fig. 6). Post-hoc tests showed that pupil diameter was significantly higher during 1- and 2-back vs. resting period ( $p<0.01$ and $p<0.001$ respectively) and signifi-

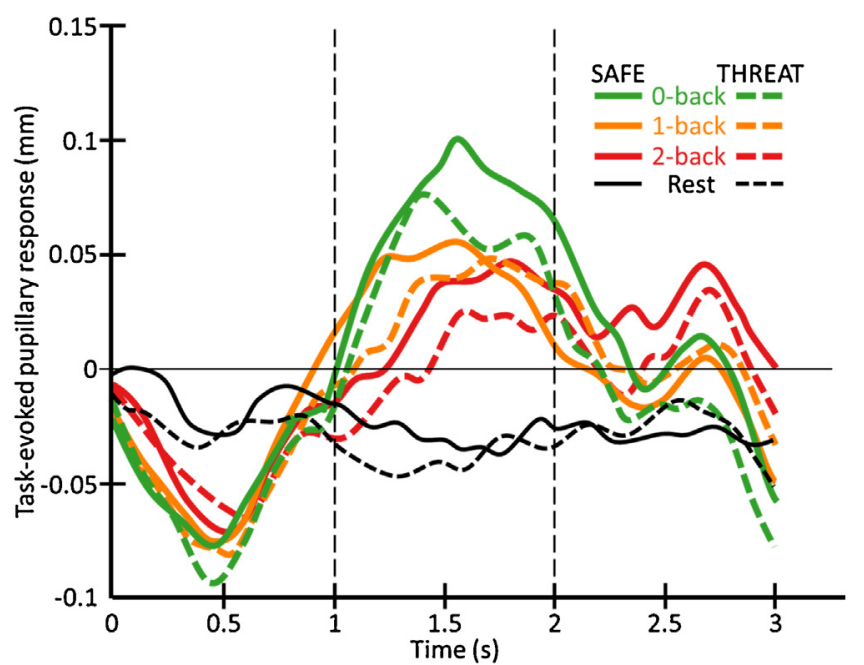

Fig. 7. Phasic pupil response. Grand-average of phasic pupil response aligned to the stimulus onset for each level of difficulty (rest, 0 -, 1-, and 2-back) and threat condition (safe and threat). Vertical lines indicate the time interval used for peak computation. $\mathrm{n}=13$.

cantly higher during 2-back compared to 0 - and 1-back $(p<0.001$ in both comparisons). There was no effect of threat on tonic pupil diameter $\left(F_{1,12}=0.75 ; \eta_{p}^{2}=0.06\right)$, neither any difficulty $\mathrm{x}$ threat interaction $\left(F_{3,36}=1.27 ; \eta_{p}^{2}=0.10\right)$.

\subsubsection{Phasic pupil response}

Phasic pupil response amplitudes (Fig. 7) significantly decreased with $n$-back task difficulty $\left(F_{3,36}=12.05 ; p<0.001 ; \eta_{p}^{2}=0.50\right)$. More precisely, a significantly higher dilation was observed in $0-, 1$ , and 2-back tasks compared to rest $(p<0.001, p<0.01$ and $p<0.05$ respectively) and dilation was greater in 0 -back vs. 2 -back $(p<0.05)$ conditions. Smaller amplitudes were observed in threat conditions $\left(F_{1,12}=6.38 ; p<0.05 ; \eta_{p}^{2}=0.35\right)$. There was no threat $\mathrm{x}$ difficulty interaction $\left(F_{3,36}=0.33 ; p>0.05 ; \eta_{p}^{2}=0.03\right)$. We conducted an additional analysis in order to assess the potential influence of the pre-stimulus baseline (median of pre-stimulus $500 \mathrm{~ms}$, used to compute the phasic response) on the results. There was an effect of $n$-back task difficulty $\left(F_{3,36}=25.38 ; p<0.001 ; \eta_{p}{ }^{2}=0.68\right)$, but no any effect of threat $\left(F_{1,12}=0.15 ; \eta_{p}^{2}=0.01\right)$ or threat $\mathrm{x}$ difficulty interaction $\left(F_{3,36}=0.56 ; \eta_{p}{ }^{2}=0.04\right)$ on pupil diameter during the pre-stimulus baseline. 

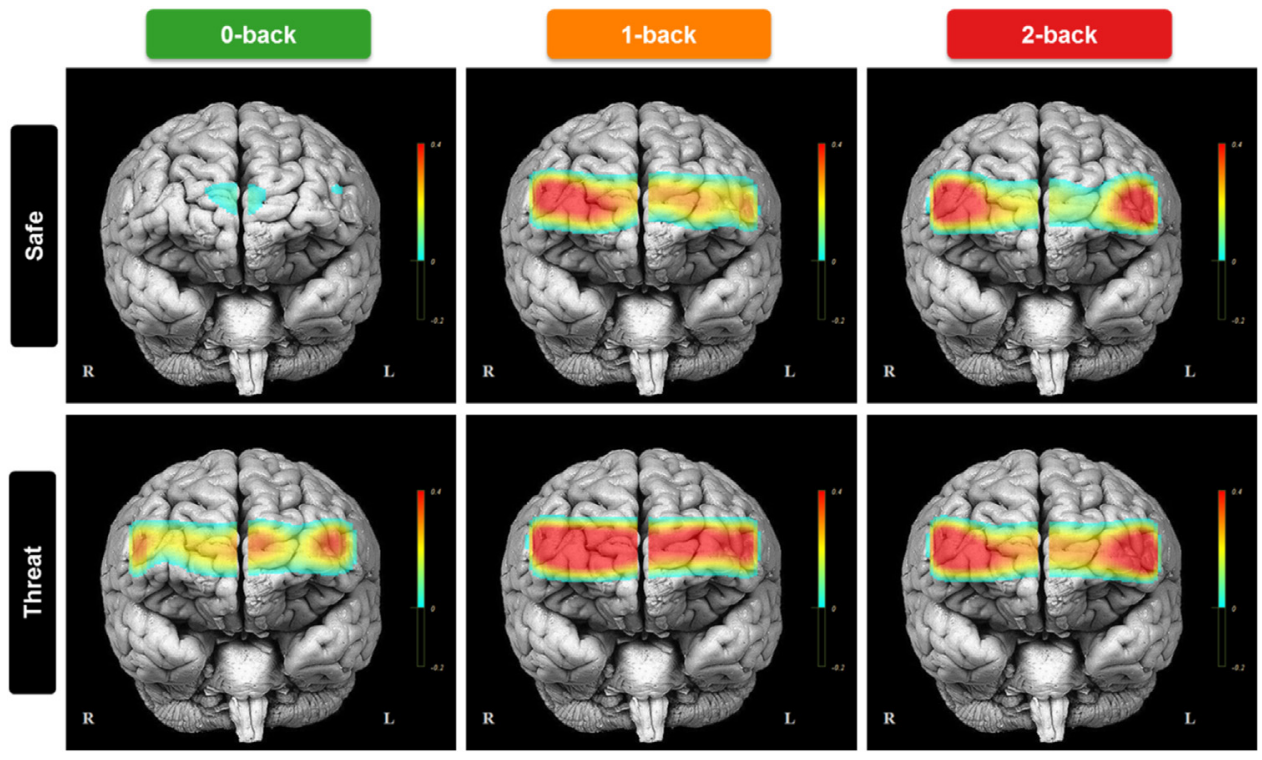

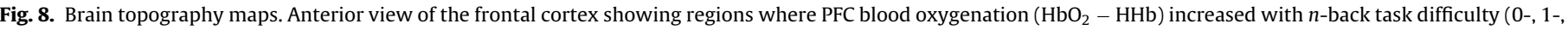
and 2-back) and threat condition (safe and threat). $\mathrm{n}=17$.

\subsection{Prefrontal cortex oxygenation changes}

Brain topography of PFC blood oxygenation is illustrated in Fig. 8. PFC blood oxygenation was dependent on $n$-back task difficulty $\left(F_{2,34}=4.14 ; p<0.05 ; \eta_{p}{ }^{2}=0.20\right)$. More precisely, it was significantly higher in 1-back vs. 0 -back condition $(p<0.05)$ and marginally higher in 2-back vs. 0 -back condition $(p=0.06)$. PFC blood oxygenation was not different in 1-back vs. 2-back condition $(p=0.96)$. The task difficulty $\mathrm{x}$ region of interest interaction was significant $\left(F_{4,68}=3.02 ; p<0.05 ; \eta_{p}^{2}=0.15\right)$. HSD revealed that difficulty had no significant effect on the frontopolar region of the prefrontal cortex $(p>0.05)$; on the contrary, oxygenation was significantly higher in the left and right prefrontal cortex in 1-back vs. 0 -back and in 2-back vs. 0-back (smallest $p$-value =0.001). As showed Fig. 8, PFC blood oxygenation was also significantly higher in threat vs. safe conditions $\left(F_{1,17}=4.81 ; p<0.05 ; \eta_{p}{ }^{2}=0.22\right)$. The task difficulty $\mathrm{x}$ stress interaction was not significant $(p>0.05)$, however, the visual inspection of Fig. 8 highlights a larger effect of threat on the prefrontal activity in the 0 -back condition in comparison to the 1-back and 2-back conditions. Coherently, effect sizes (independently of the regions of interest) showed that the strength of the impact of the threat condition was clearly larger in 0 -back condition $\left(\eta_{p}^{2}=0.39\right)$ compared to 1 -back $\left(\eta_{p}^{2}=0.04\right)$ and 2-back conditions $\left(\eta_{p}^{2}=0.04\right)$. It suggests that increasing sample size might reveal a mitigation of the effect of stress with increasing working memory load. HR was not correlated with prefrontal activity in none of the experimental conditions ( smallest $p$-value $>0.05$ ), increased prefrontal oxygenation cannot be associated with a general increase of the systemic cardiovascular activity.

\section{Discussion}

Using a novel mental arithmetic $n$-back task (i.e. Toulouse Nback Task), we examined in two separate studies how mental effort and stress impacted task performance, pupil response (study 1 ), cardiovascular activity (study 1 and 2 ), and prefrontal cortex oxygenation (study 2 ). Higher task difficulty (higher $\mathrm{n}$ level) increased perceived difficulty, degraded the performance and provoked an increased tonic pupil diameter, HR and oxygenation in the lateral prefrontal cortex, and a decreased phasic pupil response and
HRV. Importantly, the condition of stress did not impact the performance, but at the expense of a psychophysiological cost as demonstrated by lower phasic pupil response, increased HR and greater prefrontal oxygenation. These findings confirmed the psychophysiological cost of both mental effort and stress and support the common idea of the processing efficiency theory (Eysenck and Calvo, 1992) and the cognitive-energetical framework (Robert and Hockey, 1997), namely, the fact that stress can reduce human cognitive efficiency, even in the absence of a visible impact on the task performance. Stress likely triggered increased motivation and the recruitment of additional cognitive resources that minimized its aversive effects on task performance, but this was associated with a loss of cognitive efficiency.

\subsection{The psychophysiological cost of mental effort}

The increase of subjective perceived difficulty, the decrease of performance (d-prime score) and the increase in the percentage of missed responses across the three $n$-back levels confirmed that mental effort was efficiently modulated. This higher difficulty caused an increased tonic pupil diameter and HR and a decreased phasic pupil response and HRV. Classically, higher tonic pupil diameter (Beatty, 1982; Causse, Sénard, Démonet, \& Pastor, 2010; Reiner \& Gelfeld, 2014; Peysakhovich, Causse, Scannella, \& Dehais, 2015), increased HR, and decreased HRV (Riese, 1999; Causse et al., 2011a) are found under conditions of high load. Interestingly, the phasic pupil response diminished with increased difficulty, in a similar fashion than the commonly observed reduced amplitude of electroencephalography event-related potentials when resources are consumed by a high mental workload (Van Dillen \& Derks, 2012; Giraudet, St-Louis, Scannella, \& Causse, 2015; Causse et al., 2016). Contrary to tonic pupil diameter that is used to measure mental effort throughout the duration of a task, event-related phasic changes in pupil diameter relate to acute task demands (Brunyé et al., 2016). As tonic load on memory increased with the $n$ level, it is likely that fewer resources were available to process the arithmetic operations which in turn provoked a reduced phasic pupil response to these operations.

The TNT increased difficulty also yielded greater PFC oxygenation. This is consistent with previous studies showing that fNIRS 
is sensitive to WM load (Fishburn et al., 2014; Gateau et al., 2015; Herff et al., 2014; Peck et al., 2014; Yuksel et al., 2015), or mental workload, for example during an arithmetic task (Mandrick et al., 2013a). As in previous works (Fishburn et al., 2014; Owen et al., 2005; Sato et al., 2013), this increased oxygenation was rather localized in left/right lateral regions, which confirms the crucial role of the lateral regions of the prefrontal cortex in working memory processes (Curtis \& D’Esposito, 2003; Owen, Evans, \& Petrides, 1996; De Pisapia, Slomski, \& Braver, 2007) and mental arithmetic (Gruber, Indefrey, Steinmetz, \& Kleinschmidt, 2001).

\subsection{The psychophysiological cost of stress}

As suggested by Davis et al. (2010) the expectancy of an unpredictable and uncontrollable stressor should be sufficient to create a threatening context and to degrade task performance (Barrett \& Armony, 2006), at least when the pending stimulus is sufficiently aversive (Grillon et al., 2004). It has been previously shown that even quite mild stress can cause a rapid loss of cognitive abilities (Arnsten, 2009, 2015). However, in the present study, we did not observe a significant effect of the auditory stressors on task performance. Yet, the surveys conducted prior to the experiment, the ratings of the participants in the present study, and the result from the spectral frequency-temporal modulation analysis suggest that our auditory stimuli should be considered as mildly stressful. Importantly, in the light of the processing efficiency theory (Eysenck \& Calvo, 1992) and the cognitive-energetical framework (Robert and Hockey, 1997), our psychophysiological results might be interpreted as a reduced cognitive efficiency as participants might have employed cognitive strategies and compensatory effort during the stress condition in order to maintain their performance (Eysenck \& Calvo, 1992; Eysenck, Derakshan, Santos, \& Calvo, 2007). We argue that the cognitive performance effectiveness (quality of performance) in the task was not impaired by the stressors thanks to the enhanced effort and use of auxiliary processing resources and strategies, but in turn, the processing efficiency (performance effectiveness divided by effort) was markedly reduced. This reduced processing efficiency was reflected by the decreased phasic pupil response, which likely indexed the decline of the available resources to compute the arithmetic operations. The increased HR found in the threat condition confirmed that the threat of unpredictable aversive loud sounds provoked a significant elevation of the level of stress/anxiety. The amplitude of the HR elevation was consistent with results from Brosschot and Thayer (2003) study that revealed an increase of HR of approximatively 1 beat per minute after negative events.

PFC oxygenation was also more important during threat condition. This supports the idea that compensatory effort was engaged to cope with the threat. Previous neuroimaging studies showed that PFC is sensitive to emotion (Doi et al., 2013; Tupak et al., 2014), and that this brain region contributes to regulation of cognitive processes with emotion (Beer, Knight, \& D’Esposito, 2006; Hänsel \& Känel, 2008; Seo and Sinha, 2011(ch9)). Interestingly, dorsolateral PFC seems to have a pivotal role in the cognitive control of emotion (Cerqueira et al., 2008; Miller and Cohen, 2001; Robinson et al., 2013; Seo and Sinha, 2011(ch9)) and recent literature also supports the hypothesis that dorsolateral PFC regions subserves crucial function, such as executive control and working memory, that contribute to the regulation of emotion (Okon-Singer, Pessoa, \& Shackman, 2015). The executive control would act as a shield to protect cognition from the influence of emotional distractors (Clarke \& Johnstone, 2013; Robinson et al., 2013). Also, some authors have postulated that PFC exerts a control on deep brain limbic regions, such as the amygdala, in order to modulate the effects of threat. For example, Vytal, Overstreet, Charney, Robinson and Grillon (2014) showed that PFC (particularly the bilateral dorsomedial portion) sustains defensive readiness during anxiety by maintaining synchronized and coupled interaction with the bilateral amygdala. Authors stated that the connectivity between PFC and amygdala "may serve to keep the amygdala in a primed state during uncertain threat and then drive or amplify amygdala reactivity when an explicit threat is encountered". As fNIRS device used in this study could not measure deep regions of the brain, the assumption that dorsolateral PFC possibly participate in cognitive strategies to cope with the aversive effect of stress, through modulation of subcortical and limbic regions (for example, hypothalamus, hippocampus, and amygdala), should be confirmed by a future fMRI study.

Contrary to studies showing that the impact of stress is mitigated by task difficulty (Clarke \& Johnstone, 2013; Patel et al., 2015; Robinson et al., 2013), and other work showing that distracting effects are reduced when attention is strongly engaged in a task ( $\mathrm{Hu}$ et al., 2012; Pessoa et al., 2002; Van Dillen et al., 2009), or authors that put forward the idea of a dynamic balance between emotion and cognition in the brain (Drevets \& Raichle, 1998), the impact of the threat on behavior and psychophysiology was not significantly modulated by task difficulty in our study. Yet, visual inspection of the prefrontal cortex activation suggests a larger effect of threat on the prefrontal activity in the 0 -back condition in comparison to 1 back and 2-back conditions. Coherently, effect sizes (irrespectively of the regions of interest) showed that the strength of the impact of the threat condition were clearly larger in 0-back condition compared to 1-back and 2-back conditions. An increased sample size might have revealed a significant mitigation of the impact of stress on prefrontal activity by task difficulty.

\section{Conclusion}

To our knowledge, this is the first study to investigate the regulation of human performance under stress and high workload using pupil diameter, cardiovascular and prefrontal oxygenation measurements. Participants performed the Toulouse N-back Task, which mimics the multidimensional high mental workload existing in many safety-critical occupations. During the task, we induced sustained anxiety using the threat of unpredictable loud sounds, proven to be mildly stressful by surveys conducted prior and during the experiment and by results from a spectral frequency-temporal modulation analysis. We confirmed that high mental effort (generated by an increased level of working memory load) provoked increased subjective perceived difficulty, lowering of the performance, increased tonic pupil diameter and heart rate, decreased phasic pupil response and heart rate variability, and finally increased prefrontal oxygenation, particularly in the dorsolateral PFC regions. The threat of unpredictable aversive loud sounds did not impact task performance. We suggest that cognitive performance may be protected from stress thanks to the triggering of cognitive strategies and compensatory effort in order to perform the task adequately, but most likely at the expense of a psychophysiological cost as suggested by lower phasic pupil response, and increased heart rate and prefrontal oxygenation. In fine, mild stress might reduce human cognitive efficiency (because of the compensatory effort), even in the absence of a visible impact on task performance (effectiveness). The PFC seems to be a central region for mitigating the influence of stress since it subserves crucial functions that sustain coping strategies (Arnsten, 2009), such as executive control and working memory (Schmeichel et al., 2008; Okon-Singer et al., 2015). Finally, we might postulate that a more intense stress, which would have caused a strong elevation of the HR, may have finally provoked a decline of performance in the task. Thus, the present paper also calls into question the possibility to 
study visible alteration of the performance under stress with the use of the threat of aversive loud sounds.

\section{Author contributions}

MK, VP, LE, RF, and CM designed the research, and MK and VP performed the experiments. MK and VP analyzed the data. MK, CM, VP prepared the figures and wrote the manuscript. LE, RF, and CM reviewed the manuscript.

\section{Conflict of interest statement}

The authors declare that the research was conducted in the absence of any commercial or financial relationships that could be construed as a potential conflict of interest.

\section{Acknowledgements}

This work was supported by the French Research National Agency and the French Defence Procurement Agency via the Accompagnement Spécifique des travaux de Recherches et d'Innovation Défense (ASTRID).

\section{Appendix A. Supplementary data}

Supplementary data associated with this article can be found, in the online version, at http://dx.doi.org/10.1016/j.biopsycho.2016. 10.002 .

\section{References}

Andreassi, J. L. (2000). Pupillary response and behavior. psychophysiology: Human behavior \& physiological response. pp. 218-233. Mahwah, NJ: Lawrence Erlbaum Associates.

Arnsten, A. F. T. (2009). Stress signalling pathways that impair prefrontal cortex structure and function. Nature Review Neuroscience, 10(6), 410-422. http://dx doi.org/10.1038/nrn2648

Arnsten, A. F. T. (2015). Stress weakens prefrontal networks: Molecular insults to higher cognition. Nature Neuroscience, 18(10), 1376-1385. http://dx.doi.org/10. $1038 / \mathrm{nn} .4087$

Ayaz, H. (2010). Functional near infrared spectroscopy based brain computer interface PhD thesis. Philadelphia, PA: Drexel University.

Barrett, J., \& Armony, J. L. (2006). The influence of trait anxiety on autonomic response and cognitive performance during an anticipatory anxiety task. Depression and Anxiety, 23(4), 210-219. http://dx.doi.org/10.1002/da.20143

Beatty, J. (1982). Task-evoked pupillary responses, processing load, and the structure of processing resources. Psychological Bulletin, 91(2), 276-292. http:/I dx doi.org/10.1037/0033-2909.91.2.276

Beer, J. S., Knight, R. T., \& D’Esposito, M. (2006). Controlling the integration of emotion and cognition the role of frontal cortex in distinguishing helpful from hurtful emotional information. Psychological Science, 17(5), 448-453. http://dx doi.org/10.1111/j.1467-9280.2006.01726.x

Berggren, N., Richards, A., Taylor, J., \& Derakshan, N. (2013). Affective attention under cognitive load: Reduced emotional biases but emergent anxiety-related costs to inhibitory control. [Original Research]. Frontiers in Human Neuroscience, 7(188) http://dx.doi.org/10.3389/fnhum.2013.00188

Bitsios, P., Szabadi, E., \& Bradshaw, C. M. (1998). Sensitivity of the fear-inhibited light reflex to diazepam. Psychopharmacology, 135(1), 93-98.

Borghini, G., Astolfi, L., Vecchiato, G., Mattia, D., \& Babiloni, F. (2014). Measuring neurophysiological signals in aircraft pilots and car drivers for the assessment of mental workload, fatigue and drowsiness. Neuroscience $\mathcal{E}$ Biobehavioral Reviews, 44, 58-75. http://dx.doi.org/10.1016/j.neubiorev.2012.10.003

Bradley, M. M., Miccoli, L., Escrig, M. A., \& Lang, P. J. (2008). The pupil as a measure of emotional arousal and autonomic activation. Psychophysiology, 45(4), 602-607.

Breier, A., Albus, M., Pickar, D., Zahn, T. P., Wolkowitz, O. M., \& Paul, S. M. (1987). Controllable and uncontrollable stress in humans: Alterations in mood and neuroendocrine and psychophysiological function. The American Journal of Psychiatry, 144(11), 1419-1425.

Brosschot, J. F., \& Thayer, J. F. (2003). Heart rate response is longer after negative emotions than after positive emotions. International Journal of Psychophysiology, 50(3), 181-187. http://dx.doi.org/10.1016/S01678760(03)00146-6

Brunyé, T. T., Eddy, M. D., Mercan, E., Allison, K. H., Weaver, D. L., \& Elmore, J. G. (2016). Pupil diameter changes reflect difficulty and diagnostic accuracy during medical image interpretation. BMC Medical Informatics and Decision Making, 16(1), 77. http://dx.doi.org/10.1186/s12911-016-0322-3

Cacioppo, J. T., \& Tassinary, L. G. (1990). Inferring psychological significance from physiological signals. American Psychologist, 45(1), 16. http://dx.doi.org/10. 1037/0003-066X.45.1.16

Causse, M., Sénard, J.-M., Démonet, J. F., \& Pastor, J. (2010). Monitoring cognitive and emotional processes through pupil and cardiac response during dynamic versus logical task. Applied Psychophysiology and Biofeedback, 35(2), 115-123. http://dx.doi.org/10.1007/s10484-009-9115-0

Causse, M., Baracat, B., Pastor, J., \& Dehais, F. (2011). Reward and uncertainty favor risky decision-making in pilots: Evidence from cardiovascular and oculometric measurements. Applied Psychophysiology and Biofeedback, 36(4), 231-242. http://dx.doi.org/10.1007/s10484-011-9163-0

Causse, M., Dehais, F., \& Pastor, J. (2011). Executive functions and pilot characteristics predict flight simulator performance in general aviation pilots. The International Journal of Aviation Psychology, 21(3), 217-234. http://dx.doi. org/10.1080/10508414.2011.582441

Causse, M., Péran, P., Dehais, F., Caravasso, C. F., Zeffiro, T., Sabatini, U., \& Pastor, J. (2013). Affective decision making under uncertainty during a plausible aviation task: An fMRI study. Neuroimage, 71, 19-29. http://dx.doi.org/10. 1016/j.neuroimage.2012.12.060

Causse, M., Peysakhovich, V., \& Fabre, E. F. (2016). High working memory load impairs language processing during a simulated piloting task: An ERP and pupillometry study. Frontiers in Human Neuroscience, 10 http://dx.doi.org/10. 3389/fnhum.2016.00240

Cerqueira, J. J., Almeida, O. F. X., \& Sousa, N. (2008). The stressed prefrontal cortex. left? right!. Brain, Behavior, and Immunity, 22(5), 630-638. http://dx.doi.org/10. 1016/j.bbi.2008.01.005

Clarke, R. J., \& Johnstone, T. (2013). Prefrontal inhibition of threat processing reduces working memory interference. Frontiers in Human Neuroscience, 7, 228. http://dx.doi.org/10.3389/fnhum.2013.00228

Cohen, N., Moyal, N., \& Henik, A. (2015). Executive control suppresses pupillary responses to aversive stimuli. Biological Psychology, 112, 1-11. http://dx.doi. org/10.1016/j.biopsycho.2015.09.006

Curtis, C. E., \& D’Esposito, M. (2003). Persistent activity in the prefrontal cortex during working memory. Trends in Cognitive Sciences, 7(9), 415-423. http://dx. doi.org/10.1016/S1364-6613(03)00197-9

Davis, M., Walker, D. L., Miles, L., \& Grillon, C. (2010). Phasic vs sustained fear in rats and humans: Role of the extended amygdala in fear $v s$ anxiety. Neuropsychopharmacology, 35(1), 105-135. http://dx.doi.org/10.1038/npp. 2009.109

De Pisapia, N., Slomski, J. A., \& Braver, T. S. (2007). Functional specializations in lateral prefrontal cortex associated with the integration and segregation of information in working memory. Cerebral Cortex, 17(5), 993-1006. http://dx. doi.org/10.1093/cercor/bhl010

Delignières, D., Famose, J. P. \& Genty, J. (1994). Validation of a scale for the assessment of perceived task difficulty. Staps, 34, 77-88.

Doi, H., Nishitani, S., \& Shinohara, K. (2013). NIRS as a tool for assaying emotiona function in the prefrontal cortex. Frontiers in Human Neuroscience, 7, 770. http://dx.doi.org/10.3389/fnhum.2013.00770

Drevets, W. C., \& Raichle, M. E. (1998). Suppression of regional cerebral blood during emotional versus higher cognitive implications for interactions between emotion and cognition. Cognition and Emotion, 12(3), 353-385. http:// dx.doi.org/10.1080/026999398379646

Durantin, G., Gagnon, J.-F., Tremblay, S., \& Dehais, F. (2014). Using near infrared spectroscopy and heart rate variability to detect mental overload. Behavioural Brain Research, 259, 16-23. http://dx.doi.org/10.1016/j.bbr.2013.10.042

Eysenck, M. W., \& Calvo, M. G. (1992). Anxiety and performance: The processing efficiency theory. Cognition E' Emotion, 6(6), 409-434. http://dx.doi.org/10. 1080/02699939208409696

Eysenck, M. W., Derakshan, N., Santos, R., \& Calvo, M. G. (2007). Anxiety and cognitive performance: Attentional control theory. Emotion, 7(2), 336. http:// dx.doi.org/10.1037/1528-3542.7.2.336

Fishburn, F. A., Norr, M. E., Medvedev, A. V., \& Vaidya, C. J. (2014). Sensitivity of fNIRS to cognitive state and load. Frontiers in Human Neuroscience, 8, 76. http:// dx.doi.org/10.3389/fnhum.2014.00076

Gateau, T., Durantin, G., Lancelot, F. Scannella, S., \& Dehais, F. (2015). Real-Time state estimation in a flight simulator using fNIRS. PLoS One, 10(3) http://dx.doi. org/10.1371/journal.pone.0121279

Gauthier, J., \& Bouchard, S. (1993). Adaptation canadienne-française de la forme révisée du State-Trait Anxiety Inventory de Spielberger. Canadian Journal of Behavioural Science/Revue Canadienne Des Sciences Du Comportement, 25(4), 559.

Giraudet, L., St-Louis, M-E Scannella, S. \& Causse, M. (2015). P300 event-related potential as an indicator of inattentional deafness? PLoS One, 10(2), e0118556. http://dx.doi.org/10.1371/journal.pone.0118556

Grillon, C., Baas, J. P., Lissek, S., Smith, K., \& Milstein, J. (2004). Anxious responses to predictable and unpredictable aversive events. Behavioral Neuroscience, 118(5), 916-924. http://dx.doi.org/10.1037/0735-7044.118.5.916

Grillon, C., Pine, D. S., Lissek, S., Rabin, S., \& Vythilingam, M. (2009). Increased anxiety during anticipation of unpredictable aversive stimuli in posttraumatic stress disorder but not in generalized anxiety disorder. Biological Psychiatry, 66(1), 47-53. http://dx.doi.org/10.1016/j.biopsych.2008.12.028

Gruber, O., Indefrey, P., Steinmetz, H., \& Kleinschmidt, A. (2001). Dissociating neural correlates of cognitive components in mental calculation. Cerebra Cortex, 11(4), 350-359. http://dx.doi.org/10.1093/cercor/11.4.350 
Hänsel, A., \& Känel, R. (2008). The ventro-medial prefrontal cortex: A major link between the autonomic nervous system, regulation of emotion, and stress reactivity? BioPsychoSocial Medicine, 2(1), 21. http://dx.doi.org/10.1186/17510759-2-21

Herff, C., Heger, D., Fortmann, O., Hennrich, J., Putze, F., \& Schultz, T. (2014). Mental workload during n-back task-quantified in the prefrontal cortex using fNIRS. Frontiers in Human Neuroscience, 7, 935. http://dx.doi.org/10.3389/fnhum.2013. 00935

Hirano, Y., Fujita, M., Watanabe, K., Niwa, M., Takahashi, T., Kanematsu, M., ... \& Onozuka, M. (2006). Effect of unpleasant loud noise on hippocampal activities during picture encoding: An fMRI study. Brain and Cognition, 61(3), 280-285. http://dx.doi.org/10.1016/j.bandc.2006.02.003

Holm, S. (1979). A simple sequentially rejective multiple test procedure. Scandinavian Journal of Statistics, 6(2), 65-70.

Hu, K., Bauer, A., Padmala, S., \& Pessoa, L. (2012). Threat of bodily harm has opposing effects on cognition. Emotion, 12(1), 28-32. http://dx.doi.org/10. 1037/a0024345 [Washington, D.C.]

Kahneman, D., \& Beatty, J. (1966). Pupil diameter and load on memory. Science, 154(3756), 1583-1585

Kahneman, D. (1973). Attention and effort. Prentice-Hall.

Kleiner, M., Brainard, D., \& Pelli. (2007). What's new in psychtoolbox-3? Perception, 36. ECVP Abstract Supplement.

Kumar, S., Forster, H. M., Bailey, P., \& Griffiths, T. D. (2008). Mapping unpleasantness of sounds to their auditory representation. The Journal of the Acoustical Society of America, 124(6), 3810-3817. http://dx.doi.org/10.1121/1. 3006380

Laeng, B., Sirois, S., \& Gredebäck, G. (2012). Pupillometry a window to the preconscious? Perspectives on Psychological Science, 7(1), 18-27.

Lane, R. D., McRae, K., Reiman, E. M., Chen, K., Ahern, G. L., \& Thayer, J. F. (2009). Neural correlates of heart rate variability during emotion. Neuroimage, 44(1), 213-222. http://dx.doi.org/10.1016/j.neuroimage.2008.07.056

Levy, R., \& Goldman-Rakic, P. S. (2000). Segregation of working memory functions within the dorsolateral prefrontal cortex Executive control and the frontal lobe: Current issues. pp. 23-32. Springer.

Lupien, S. J., Maheu, F., Tu, M., Fiocco, A., \& Schramek, T. E. (2007). The effects of stress and stress hormones on human cognition: Implications for the field of brain and cognition. Brain and Cognition, 65(3), 209-237. http://dx.doi.org/10. 1016/j.bandc.2007.02.007

Mandrick, K., Derosiere, G., Dray, G., Coulon, D., Micallef, J.-P., \& Perrey, S. (2013a). Prefrontal cortex activity during motor tasks with additional mental load requiring attentional demand: A near-infrared spectroscopy study. Neuroscience Research, 76(3), 156-162. http://dx.doi.org/10.1016/j.neures. 2013.04.006

Mandrick, K., Derosiere, G., Dray, G., Coulon, D., Micallef, J.-P., \& Perrey, S. (2013b) Utilizing slope method as an alternative data analysis for functional near-infrared spectroscopy-derived cerebral hemodynamic responses. International Journal of Industrial Ergonomics, 43(4), 335-341. http://dx.doi.org/ 10.1016/j.ergon.2013.05.003

McCraty, R., Atkinson, M., Tiller, W. A., Rein, G., \& Watkins, A. D. (1995). The effects of emotions on short-term power spectrum analysis of heart rate variability. The American Journal of Cardiology, 76(14), 1089-1093. http://dx.doi.org/10. 1016/S0002-9149(99)80309-9

Miller, E. K., \& Cohen, J. D. (2001). An integrative theory of prefrontal cortex function. Annual Review of Neuroscience, 24(1), 167-202. http://dx.doi.org/10. 1146/annurev.neuro.24.1.167

Morinaga, K., Akiyoshi, J., Matsushita, H., Ichioka, S., Tanaka, Y., Tsuru, J., \& Hanada, H. (2007). Anticipatory anxiety-induced changes in human lateral prefrontal cortex activity. Biological Psychology, 74(1), 34-38. http://dx.doi.org/10.1016/j. biopsycho.2006.06.005

Okon-Singer, H., Hendler, T., Pessoa, L., \& Shackman, A. J. (2015). The neurobiology of emotion-cognition interactions: Fundamental questions and strategies for future research. Frontiers in Human Neuroscience, 9(58) http://dx.doi.org/10. 3389/fnhum.2015.00058

Owen, A. M., Evans, A. C., \& Petrides, M. (1996). Evidence for a two-Stage model of spatial working memory processing within the lateral frontal cortex: A positron emission tomography study. Cerebral Cortex, 6(1), 31-38.

Owen, A. M., McMillan, K. M., Laird, A. R., \& Bullmore, E. (2005). N-back working memory paradigm: A meta-analysis of normative functional neuroimaging studies. Human Brain Mapping, 25(1), 46-59. http://dx.doi.org/10.1002/hbm 20131

Partala, T., \& Surakka, V. (2003). Pupil size variation as an indication of affective processing. International Journal of Human-computer Studies, 59(1), 185-198.

Patel, N., Vytal, K., Pavletic, N., Stoodley, C., Pine, D. S., Grillon, C., \& Ernst, M. (2015). Interaction of threat and verbal working memory in adolescents. Psychophysiology, http://dx.doi.org/10.1111/psyp.12582

Peck, E. M., Afergan, D., Yuksel, B. F., Lalooses, F., \& Jacob, R. J. K. (2014). Using fNIRS to measure mental workload in the real world. In S. H. Fairclough, \& K. Gilleade (Eds.), Advances in physiological computing (pp. 117-139). London: Springer [Consulté à l'adresse]. http://link.springer.com/chapter/10.1007/978-1-44716392-3_6

Pessoa, L., McKenna, M., Gutierrez, E., \& Ungerleider, L. G. (2002). Neural processing of emotional faces requires attention. Proceedings of the National Academy of Sciences of the United States of America, 99(17), 11458-11463. http://dx.doi.org/10.1073/pnas.172403899

Peysakhovich, V., Causse, M., Scannella, S., \& Dehais, F. (2015). Frequency analysis of a task-evoked pupillary response: Luminance-independent measure of mental effort. International Journal of Psychophysiology, 97(1), 30-37. http://dx. doi.org/10.1016/j.ijpsycho.2015.04.019

Qin, S., Hermans, E. J., van Marle, H. J. F., Luo, J., \& Fernández, G. (2009). Acute psychological stress reduces working memory-related activity in the dorsolateral prefrontal cortex. Biological Psychiatry, 66(1), 25-32. http://dx.doi. org/10.1016/j.biopsych.2009.03.006

Quintana, D. S., Guastella, A. J., Outhred, T., Hickie, I. B., \& Kemp, A. H. (2012). Heart rate variability is associated with emotion recognition: Direct evidence for a relationship between the autonomic nervous system and social cognition. International Journal of Psychophysiology, 86(2), 168-172. http://dx.doi.org/10. 1016/j.ijpsycho.2012.08.012

Reiner, M., \& Gelfeld, T. M. (2014). Estimating mental workload through event-related fluctuations of pupil area during a task in a virtual world. International Journal of Psychophysiology, 93(1), 38-44. http://dx.doi.org/10. 1016/j.ijpsycho.2013.11.002

Riese, H. (1999). Mental fatigue after very severe closed head injury: Sustained performance, mental effort, and distress at two levels of workload in a driving simulator. Neuropsychological Rehabilitation, 9(2), 189-205. http://dx.doi.org/ $10.1080 / 713755600$

Robert, G., \& Hockey, J. (1997). Compensatory control in the regulation of human performance under stress and high workload: A cognitive-energetical framework. Biological Psychology, 45(1), 73-93. http://dx.doi.org/10.1016/ S0301-0511(96)05223-4

Robinson, O. J., Vytal, K., Cornwell, B. R., \& Grillon, C. (2013). The impact of anxiety upon cognition: Perspectives from human threat of shock studies. Frontiers in Human Neuroscience, 7, 203. http://dx.doi.org/10.3389/fnhum.2013.00203

Ryu, K., \& Myung, R. (2005). Evaluation of mental workload with a combined measure based on physiological indices during a dual task of tracking and mental arithmetic. International Journal of Industrial Ergonomics, 35(11), 991-1009. http://dx.doi.org/10.1016/j.ergon.2005.04.005

Salzman, C. D., \& Fusi, S. (2010a). Emotion, cognition, and mental state representation in amygdala and prefrontal cortex. Annual Review of Neuroscience, 33, 173. http://dx.doi.org/10.1146/annurev.neuro.051508. 135256

Salzman, C. D., \& Fusi, S. (2010b). Emotion, cognition, and mental state representation in amygdala and prefrontal cortex. Annual Review of Neuroscience, 33, 173-202. http://dx.doi.org/10.1146/annurev.neuro.051508. 135256

Sato, H., Yahata, N., Funane, T., Takizawa, R., Katura, T., Atsumori, H., . . . \& Kasai, K (2013). A NIRS? fMRI investigation of prefrontal cortex activity during a working memory task. Neuroimage, http://dx.doi.org/10.1016/j.neuroimage. 2013.06.043

Schmeichel, B. J., Volokhov, R. N., \& Demaree, H. A. (2008). Working memory capacity and the self-regulation of emotional expression and experience. Journal of Personality and Social Psychology, 95(6), 1526. http://dx.doi.org/10. 1037/a0013345

Schoofs, D., Wolf, O., \& Smeets, T. (2009). Cold pressor stress impairs performance on working memory tasks requiring executive functions in healthy young men. Behavioral Neuroscience, 123(5), 1066-1075.

Seo, D., \& Sinha, R. (2011). Neural mechanisms of stress and addiction. In B. Adinoff \& E. A. Stein (Eds.), Neuroimaging in addiction (pp. 209-233). Chichester, UK: John Wiley \& Sons, Ltd. http://dx.doi.org/10.1002/9781119998938

Spielberger, C. D., Gorsuch, R. L., \& Lushene, R. E. (1970). State-Trait anxiety inventory. CA: Consulting Psychologists Press.

Starcke, K., Wiesen, C., Trotzke, P., \& Brand, M. (2016). Effects of acute laboratory stress on executive functions. [Original research]. Frontiers in Psychology, 7(461) http://dx.doi.org/10.3389/fpsyg.2016.00461

Tanida, M., Katsuyama, M., \& Sakatani, K. (2007). Relation between mental stress-induced prefrontal cortex activity and skin conditions: A near-infrared spectroscopy study. Brain Research, 1184, 210-216. http://dx.doi.org/10.1016/j. brainres.2007.09.058

Task Force of the European Society of Cardiology the North American Society of Pacing. (1996). Heart rate variability standards of measurement, physiological interpretation, and clinical use. Circulation, 5, 1043. http://dx.doi.org/10.1161/ 01. CIR.93.5.1043

Tupak, S. V., Dresler, T., Guhn, A., Ehlis, A.-C., Fallgatter, A. J., Pauli, P., \& Herrmann, M. J. (2014). Implicit emotion regulation in the presence of threat: Neural and autonomic correlates. Neuroimage, 85(Part 1), 372-379. http://dx.doi.org/10. 1016/j.neuroimage.2013.09.066

Van Dillen, L. F., Heslenfeld, D. J., \& Koole, S. L. (2009). Tuning down the emotional brain: An fMRI study of the effects of cognitive load on the processing of affective images. Neuroimage, 45(4), 1212-1219. http://dx.doi.org/10.1016/j. neuroimage.2009.01.016

Vytal, K. E., Overstreet, C., Charney, D. R., Robinson, O. J., \& Grillon, C. (2014) Sustained anxiety increases amygdala-dorsomedial prefrontal coupling: A mechanism for maintaining an anxious state in healthy adults. Journal of Psychiatry \& Neuroscience: JPN, 39(5), 321-329.

Yuksel, B. F., Peck, E. M., Afergan, D., Hincks, S. W., Shibata, T., Kainerstorfer, J., . . \& \& Jacob, R. J. K. (2015). Functional near-infrared spectroscopy for adaptive human-computer interfaces (Vol. 9319, p. 93190R-93190R-9). http://dx.doi.org/ $10.1117 / 12.2075929$

Zald, D. H., \& Pardo, J. V. (2002). The neural correlates of aversive auditory stimulation. NeuroImage, 16(3, Part A), 746-753. http://dx.doi.org/10.1006 nimg.2002.1115 
Zhou, F., Ou, X., Helander, M. G., \& Jiao, J. R. (2011). Affect prediction from physiological measures via visual stimuli. International Journal of Human-Computer Studies, 69(12), 801-819. http://dx.doi.org/10.1016/j.ijhcs. 2011.07.005

\section{Further reading}

Chi, T., Ru, P., \& Shamma, S.A., 2005. Multiresolution spectrotemporal analysis of complex sounds. The Journal of the Acoustical Society of America. 118(2) 887-906. doi: 10.1121/1.1945807.
Kumar, S., Kriegstein, K., Friston, Von, \& Griffiths, K. 2012. Features versus feelings: Dissociable representations of the acoustic features and valence of aversive sounds, The Journal of Neuroscience, 32(41) 14184-14192. doi:10.1523/jneurosci.1759-12.2012.

Shamma, S. 2003. Encoding sound timbre in the auditory system IETE, Journal of Research, 49(2-3) 145-156 